\title{
Neotenic phenomenon in gene expression in the skin of Foxn1- deficient (nude) mice - a projection for regenerative skin wound healing
}

Anna Kur-Piotrowska', Marta Kopcewicz' , Leslie P. Kozak', Pawel Sachadyn², Anna Grabowska and Barbara Gawronska-Kozak ${ }^{1 *}$

\begin{abstract}
Background: Mouse fetuses up to 16 day of embryonic development and nude (Foxn1- deficient) mice are examples of animals that undergo regenerative (scar-free) skin healing. The expression of transcription factor Foxn1 in the epidermis of mouse fetuses begins at embryonic day 16.5 which coincides with the transition point from scar-free to scar-forming skin wound healing. In the present study, we tested the hypothesis that Foxn1 expression in the skin is an essential condition to establish the adult skin phenotype and that Foxn1 inactivity in nude mice keeps skin in the immature stage resembling the phenomena of neoteny.

Results: Uninjured skin of adult C57BL/6J (B6) mice, mouse fetuses at days 14 (E14) and 18 (E18) of embryonic development and B6.Cg-Foxn1 nu (nude) mice were characterized for their gene expression profiles by RNA sequencing that was validated through qRT-PCR, Western Blot and immunohistochemistry. Differentially regulated genes indicated that nude mice were more similar to E14 (model of regenerative healing) and B6 were more similar to E18 (model of reparative healing). The up-regulated genes in nude and E14 mice were associated with tissue remodeling, cytoskeletal rearrangement, wound healing and immune response, whereas the down-regulated genes were associated with differentiation. E14 and nude mice exhibit prominent up-regulation of keratin (Krt23, -73, -82, -16, -17), involucrin (Ivl) and filaggrin (Flg2) genes. The transcription factors associated with the Hox genes known to specify cell fate during embryonic development and promote embryonic stem cells differentiation were down-regulated in both nude and E14. Among the genes enriched in the nude skin but not shared with E14 fetuses were members of the Wnt and matrix metalloproteinases (Mmps) families whereas Bmp and Notch related genes were down-regulated.

Conclusions: In summary, Foxn1 appears to be a pivotal control element of the developmental program and skin maturation. Nude mice may be considered as a model of neoteny among mammals. The resemblance of gene expression profiles in the skin of both nude and E14 mice are direct or indirect consequences of the Foxn1 deficiency. Foxn1 appears to regulate the balance between cell proliferation and differentiation and its inactivity creates a pro-regenerative environment.
\end{abstract}

Keywords: Transcriptome, Next-generation sequencing, Regeneration, Mmp-9

\footnotetext{
*Correspondence: b.kozak@pan.olsztyn.pl

'Institute of Animal Reproduction and Food Research, Polish Academy of

Sciences, ul. Tuwima 10, 10-748 Olsztyn, Poland

Full list of author information is available at the end of the article
} 


\section{Background}

The maintenance of skin as a barrier that protects the host from the external environment requires a vigilant state in order to respond immediately to external, often unexpected, insults. Following injury, skin can heal by regenerative (scar-free) or reparative (scar-forming) processes. Regenerative skin healing, so common among lower vertebrates [1-3], is almost absent in adult mammals. In 1979, Rowlatt reported in his seminal paper that human fetuses are capable of regenerative (scar-free) response to skin wounds [4]. Follow-up studies showed that mammalian fetuses heal skin injuries in a scar-free way, if the injury occurs during first two trimesters of gestation. Thereafter, skin lesions heal with scar formation (in the reparative type of healing). The transition from scarless, fetal-type repair to adult-type repair with scarring occurs between days 16.5 and 18.5 of gestation for mice and rats [5] and 24 weeks for humans [6]. Comprehensive studies on regeneration in fetal skin have uncovered important differences between fetal and adult skin and identified factors that are prerequisites for scar-free healing; however, key pathways responsible for regenerative healing remain to be determined [7].

Recently, our laboratory introduced a genetic mouse model to determine the underlying mechanisms of scarfree healing by showing that adult nude (Foxn1-deficient) mice, similar to mammalian fetuses, are able to heal their skin injuries in a scar-free way [8-10]. To explore the possible mechanisms of skin regeneration, mouse models with variable immune-competency were examined to assess whether the immunodeficiency of nude mice involving the lack of thymus or T-lymphocytes could explain scar-free skin healing [8]. Although the results of the studies do not challenge the contribution of inflammatory response in the outcome of skin wound healing, they showed that the lack of thymus and/or T-cells was not a condition for scarless healing [8].

The nude phenotype is the consequence of a spontaneous point mutation in the forkhead box N1 (Foxn1) gene which encodes a transcriptional factor expressed in epithelial cells of the thymus, a distinct population of keratinocytes in the epidermis, and hair follicles. The pleiotropic effects of the Foxn1 mutation are manifested by a lack of thymus, primary T-cell deficiency and hairless skin in mice, rats and humans. Studies on the role of Foxn1 in skin and hair development, although not as extensive as on the thymus, indicate that Foxn1 participates in hair follicle development, promotes keratinocyte differentiation and stimulates signal transduction between melanocytes and keratinocytes participating in the pigmentation process. Developmental studies by Brissette et al. showed that in the skin, Foxn1 expression begins around the mouth and nose area at day 14 , then spreads over the entire skin by days $16-17$ of embryonic development in mice [11]. This pattern of expression coincides with the transition from scarfree to scar-forming skin healing in mouse fetuses at day 16 of gestation. It is conceivable that a loss-offunction mutation in Foxn1 in nude mice and the lack of normal Foxn1 expression during the scar-free healing phase in mammalian fetuses provide conditions favorable to regeneration. Moreover, our recent data revealed that Foxn1 can act as a regulator of the skin wound healing process. The experiments performed on Foxn1::Egfp transgenic mice showed that Foxn1-bearing cells participate in the wound healing process through engagement in re-epithelialization and possible involvement in scar formation due to Foxn1 activity during the epithelial-to-mesenchymal transition (EMT) [12]. In the present study using next-generation high-throughput DNA sequencing techniques, we aimed to test the hypothesis that Foxn1 expression in the skin is an essential condition for establishing the adult skin phenotype and that a lack of Foxn1 maintains skin in a neoteny stage (immature stage of development). We predict that Foxn1- null mice (nude mice) are neotenic in the transcriptomic signature of their skin.

\section{Results and discussion}

In the present study, we have used two unique models of true regeneration among mammals, mouse fetuses at the $14^{\text {th }}$ day of embryonic development (E14) and nude mice, and genome-wide analysis of gene expression to uncover the transcriptional signature of scar-free skin healing. We hypothesize that uninjured skin of E14 fetuses and nude mice share a transcriptomic signature that predisposes them to regenerative skin healing when wounding occurs. In order to establish gene expression profiles in nude and E14 mice, we performed RNA-seq analysis of uninjured skin and epidermis from 6-week old C57BL/6J (B6) and B6.Cg-Foxn1 nu (nude), and skin from B6 fetuses at E14 and E18 day of embryonic development. To exclude differences that can arise from different genetic backgrounds, we used mice on C57BL/6J genetic background. Previous microarray studies, including a comparison of gene expression between cultured dermal fibroblasts isolated from E16.5 and E18.5 fetuses and cultured keratinocytes transfected with Foxn1, provided important insight into regenerative response genes $[13,14]$. However, the obtained results are highly influenced by culture conditions and the manipulation of Foxn1 transfection $[13,14]$. In contrast to previous studies, we performed the analysis on intact skin to avoid in vitro culture artifacts. We are aware that our analyses are complicated due to the mixture of cellular skin components, such as keratinocytes, melanocytes, and Langerhans cells in the epidermis and dermal fibroblasts; 
endothelial cells; preadipocytes/adipocytes; and inflammatory cells in the dermis, among others. Nevertheless, wound healing is undoubtedly a process that involves multiple cell types interacting.

\section{Differential gene expression in skin and epidermis among: nude, B6, E14 and E18 mice}

In the first step of analysis, we compared the transcriptomes from the skin of nude mice (regenerative) to transcriptomes from both adult B6 (reparative) and E14 (regenerative) mice. Subsequently, the transcriptomes from E18 (reparative) skin samples were compared with transcriptomes from both E14 (regenerative) and adult B6 (reparative) skin (Fig. 1a).

In this manner, we generated lists of genes showing statistically significant differences in expression (http:// www.ncbi.nlm.nih.gov/geo/query/acc.cgi?acc=GSE71619).

For further analysis we used genes considered as a differentially expressed when changes in the expression were greater than or equal to two-fold. The comparison of skin gene expression between nude (model of skin regeneration) and B6 (model of skin reparation) showed 2243 genes that were variably expressed (up and down) (Fig. 1a). Similarly, 2065 genes were differentially regulated (up and down) in the comparison between the skin from E14 (regenerative) and E18 (reparative) fetuses (Fig. 1a). These numbers clearly demonstrate huge differences in gene expression between regenerative (nude and E14) vs reparative (B6 and E18) models of healing. In contrast to these data, the diversity in the number of differentially expressed genes between mice displaying similar characteristics of healing is smaller. The expression profile of E18 fetuses shows much higher similarity to the profile of adult 6 week-old B6 mice; as only 96 genes were found to be differentially expressed (Fig. 1a). Interestingly, the number of differentially expressed genes in adult nude vs E14 fetuses (1451) is considerably lower than the number of genes that differed between adult nude (regenerative) vs adult B6 (reparative) (2243) (Fig. 1a).

The nude phenotype results from the inactivity of transcription factor Foxn1 whose expression in the skin is restricted to epidermis. Therefore, we performed further analysis to identify the differentially regulated genes in the epidermis isolated from nude and B6 skin (Fig. 1b). The comparison revealed that 306 genes were downregulated and 571 genes were up-regulated 2-fold and higher in nude epidermis. Such a substantial number of differentially regulated genes that are potent direct and indirect targets of Foxn1 suggests that this transcription factor broadly influences epidermis at the molecular and consequently physiological levels.

Since a number of differentially regulated genes in the first analysis (for example, nude vs E14, see Fig. 1a) may be partially due to the induction and repression of genes associated with developmental processes for E14, in the next step we sought to identify genes that are similarly regulated for nude and E14 mice (Fig. 1c). For this purpose we compared data from two analyses: nude vs B6 (2243 differently regulated genes) to E14 vs E18 (2065 differently regulated genes). We found that among the up-regulated genes in nude vs B6 (1069 genes) and E14 vs E18 (564 genes), 193 are common for nude and E14 (Fig. 1c; Additional file 1: Table S1.). The analysis showed that among 1174 genes down-regulated for nude vs B6 and 1501 for E14 vs E18, 465 genes were common for nude and E14 (Fig. 1c; Additional file 2: Table S2). The greater number of down-regulated vs up-regulated genes in regenerative skin tissues supports the concept proposed by Mercer et al. that the large number of down-regulated genes suggests that the loss of their activity plays significant roles in induction and maintenance of regeneration [15].

\section{Functional annotation terms grouped according to their biological meaning enriched in nude and E14 skin and nude epidermis}

In the next step of the analysis, we focused on the list of differentially expressed genes shared between nude and E14 mice (Fig. 1c; Additional file 1: Table S1 and Additional file 2: Table S2). Genes associated with tissue remodeling, cytoskeletal rearrangements, wound healing and the immune response showed up-regulation in nude and E14 skin tissues, while those related to differentiation were down-regulated (Table 1). Similar gene categories associated with matched molecular and cellular functions have been suggested to influence the outcome of injury in other models of regeneration: lower vertebrates [16] and the MRL mouse [17].

Among the most commonly up-regulated genes that were involved in tissue remodeling and extracellular matrix composition in common for nude and E14 are kallikreins and kallikrein-related peptidases including Klk7, Klk8 and Klk10 and protease serine 27 (Prss27) (Table 1). It has been suggested that Klk8 stimulates keratinocyte proliferation or differentiation depending on the stage of wound healing and its up-regulation in nude mouse skin was previously detected $[18,19]$. Li et al. observed that Prss27, which is also up-regulated in nude and E14 according to our analysis (Table 1), was found in skin only during epidermal hyperproliferation associated with wound closure [20]. They suggested that Prss27 function is associated with re-epithelialization and terminal differentiation of keratinocytes. It is reported that Prss 27 and Foxn 1 are localized to the suprabasal layer of the epidermis [20]. Considering that Foxn1 acts as a transcriptional activator and it is responsible for the initial stages of differentiation in keratinocytes, 

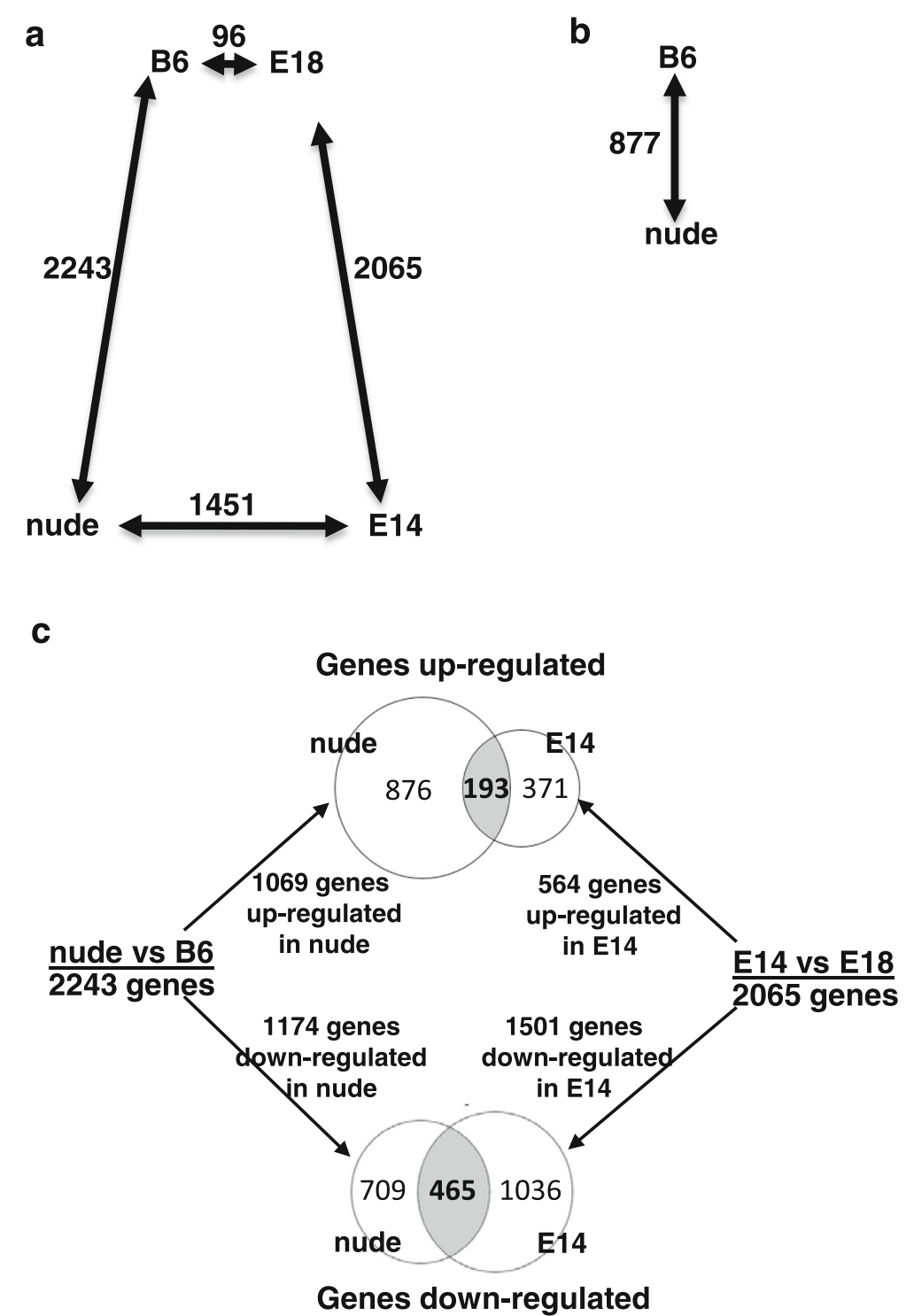

Fig. 1 Comparison of the numbers of genes differentially regulated in skin (a) and epidermis (b). Genes that are up- and down-regulated in common for nude and E14 (c). B6 (C57BL/6); 6 weeks old), nude (B6.Cg-Foxn1 nu; 6 weeks old), E14 (C57BL/6); 14 day of embryonic development) and E18 (C57BL/6); 18 day of embryonic development). Numbers next to arrows specify the number of genes that are differentially expressed (using a cutoff threshold of 2fold difference). Length of arrows indicates the relative abundance of differently regulated genes between groups (a) and (b). The analysis was performed as an overlay of gene lists from two tested sets of genes: nude vs B6 and E14 vs E18 (c)

the upregulation of Prss27 in the nude skin seems to be an indirect consequence of Foxn1 deficiency [20].

A number of extracellular factors and stimuli (like injury) alter cell behaviors that are mirrored by changes in keratinocyte cytoskeleton and the architecture of the epidermis. E14 and nude mice exhibit prominent upregulation of keratin (Krt) genes (Krt23, -73, -82, -16, -17) in the skin and $K r t 6 a$ and $-6 b$ in nude epidermis (Table 1, Additional file 3: Table S3). Krt6, -16 and -17 are biomarkers of keratinocytes in an activated (hyperproliferative) state [21]. Interestingly, elevated levels of $K r t 6 a,-6 b$ and -16 were also detected in uninjured digital tips of the MRL mouse, the strain which displays features of enhanced regenerative abilities [22]. Moreover, mouse embryos and post-injured skin of Acomys (regenerative) mice exhibit elevated levels of keratins transcripts (Krt6, -16, -17) [23, 24].

As keratinocytes switch from proliferation to differentiation, they begin to synthesize cornified envelope protein precursors $[25,26]$. Involucrin (Ivl), filaggrin (Flg2), small proline-rich protein $2 \mathrm{~d}$ (Sprr2d) and repetin (Rptn) belong to this class of peptides and all are significantly upregulated in E14 (skin) and nude (skin and epidermis) tissues (Table 1). It was showed that over-expression of 
Table 1 Selected genes enriched in differentially expressed transcripts nude and E14 skin and relevant functional categories. For epidermis the analysis relays on the comparison of genes differently regulated between nude and B6

\begin{tabular}{|c|c|c|c|c|c|c|}
\hline \multirow{3}{*}{$\begin{array}{l}\text { Functional categories and } \\
\text { representative genes }\end{array}$} & \multicolumn{4}{|l|}{ Skin } & \multirow{2}{*}{\multicolumn{2}{|c|}{$\frac{\text { Epidermis }}{\text { nude }}$}} \\
\hline & \multicolumn{2}{|l|}{ E14 } & \multicolumn{2}{|l|}{ nude } & & \\
\hline & up (p-value) & down ( $p$-value) & up (p-value) & down ( $p$-value) & up (p-value) & down ( $p$-value) \\
\hline \multicolumn{7}{|l|}{ Tissue remodeling } \\
\hline Zymogen & $\times\left(1.2 \times 10^{-8}\right)$ & & $\times\left(4.5 \times 10^{-9}\right)$ & & & \\
\hline Endopeptidase activity & $\times\left(7.1 \times 10^{-2}\right)$ & & $\times\left(9.3 \times 10^{-2}\right)$ & & & \\
\hline Metallopeptidase & $\times\left(2.3 \times 10^{-2}\right)$ & & $\times\left(2.4 \times 10^{-3}\right)$ & & & \\
\hline Protease & $\times\left(5.0 \times 10^{-5}\right)$ & & $\times\left(1.5 \times 10^{-6}\right)$ & & & \\
\hline KIk10, kallikrein related-peptidase 10 & 10.66 & & 63.36 & & 2.61 & \\
\hline KIk7, kallikrein related-peptidase 7 & 11.14 & & 10.95 & & 2.15 & \\
\hline KIk8, kallikrein related-peptidase 8 & 3.22 & & 4.26 & & & \\
\hline Prss 27 , protease serine 27 & 8.68 & & 29.83 & & 5.19 & \\
\hline \multicolumn{7}{|l|}{ Cytoskeletal rearrangments } \\
\hline Keratinization & $\times\left(3.8 \times 10^{-2}\right)$ & & $\times\left(8.9 \times 10^{-4}\right)$ & & $\times\left(4.9 \times 10^{-2}\right)$ & \\
\hline Keratin & & & $\times\left(3.2 \times 10^{-8}\right)$ & & & \\
\hline Cornified envelope & $\times\left(4.6 \times 10^{-5}\right)$ & & $\times\left(3.9 \times 10^{-7}\right)$ & & $\times\left(1.6 \times 10^{-8}\right)$ & \\
\hline Keratinocyte differentiation & $\times\left(1.5 \times 10^{-2}\right)$ & & $\times\left(1.8 \times 10^{-4}\right)$ & & $\times\left(1.9 \times 10^{-4}\right)$ & \\
\hline Krt23, keratin 23 & 12.06 & & 7.86 & & & \\
\hline Krt73, keratin 73 & 8.35 & & 17.89 & & 3.85 & \\
\hline Krt82, keratin 82 & 2.8 & & 3.25 & & 2.2 & \\
\hline Krt17, keratin 17 & 9.14 & & 27.58 & & 2.61 & \\
\hline Krt16, keratin 16 & 13.3 & & 33.43 & & 3.69 & \\
\hline Sprr2d, small proline-rich protein & 15.66 & & 12.88 & & 4.71 & \\
\hline Flg2, filaggrin family member 2 & 21.31 & & & & & \\
\hline Rptn, repetin & 4.65 & & 34.82 & & 3.85 & \\
\hline$|V|$, involucrin & 14.62 & & 6.9 & & 4.45 & \\
\hline \multicolumn{7}{|l|}{ Wound healing and immune response } \\
\hline Inflammatory response & $\times\left(1.8 \times 10^{-7}\right)$ & & $\times\left(8.3 \times 10^{-13}\right)$ & & $\times\left(2.8 \times 10^{-2}\right)$ & \\
\hline Chemokine activity & $\times\left(1.7 \times 10^{-5}\right)$ & & $\times\left(6.2 \times 10^{-6}\right)$ & & $\times\left(8.6 \times 10^{-2}\right)$ & \\
\hline $\begin{array}{l}\text { Positive regulation of T cell } \\
\text { differentiation }\end{array}$ & $\times\left(5.2 \times 10^{-3}\right)$ & & $\times\left(1.9 \times 10^{-2}\right)$ & & & \\
\hline Fn1, fibronectin 1 & 2.49 & & 2.77 & & & \\
\hline II-18, interleukin 18 & 7.47 & & 5.07 & & & \\
\hline$\|-1 A$, interleukin 1 alpha & 6.32 & & 7.75 & & & \\
\hline II-1 F6, interleukin-1 epsilon (IIe) & 13.67 & & 12.27 & & 4.34 & \\
\hline II-1 F8, interleukin 1 family, member 8 & 9.67 & & 10.45 & & 4.15 & \\
\hline $11-5$, interleukin 5 & 2.5 & & 3.14 & & & \\
\hline \multicolumn{7}{|l|}{ Differentiation } \\
\hline Differentiation & & $\times\left(2.3 \times 10^{-4}\right)$ & & $\times\left(1.6 \times 10^{-4}\right)$ & & $\times\left(1.5 \times 10^{-3}\right)$ \\
\hline Developmental protein & & $\times\left(5.8 \times 10^{-11}\right)$ & & $\times\left(3.0 \times 10^{-17}\right)$ & & $\times\left(2.8 \times 10^{-2}\right)$ \\
\hline Foxd1, forkhead box D1 & & 4.47 & & 4.32 & & \\
\hline Gbx2, gastrulation brain homeobox 2 & & 18.2 & & 7.65 & & \\
\hline Hoxb3, homeobox B3. transcript variant 2 & & 4.08 & & 2.41 & & \\
\hline Hoxb5, homeobox B5 & & 5.83 & & 3.7 & & \\
\hline
\end{tabular}


Table 1 Selected genes enriched in differentially expressed transcripts nude and E14 skin and relevant functional categories. For epidermis the analysis relays on the comparison of genes differently regulated between nude and B6 (Continued)

\begin{tabular}{lll}
\hline Hoxc6, homeobox C6 & 3.66 & 9.66 \\
Hoxd13, homeobox D13 & 6.33 & 5.39 \\
Pax1, paired box gene 1 & 8.94 & 9.47 \\
Phox26, paired-like homeobox 2b & 7.11 & 9.39 \\
$\begin{array}{l}\text { Pitx1, paired-like homeodomain } \\
\text { transcription factor 1 }\end{array}$ & 6.57 & 7.34 \\
$\begin{array}{l}\text { Six1, sine oculis-related homeobox1 } \\
\text { homolog (Drosophila) }\end{array}$ & 4.07 & 8.29 \\
Six2, six2. complete sequence & & 10.96 \\
\hline
\end{tabular}

Foxn1 results in increased expression of early differentiation markers (Krt1) and reduced expression of late differentiation markers, such as Ivl and Flg2 [27, 28]. It is not surprising that lack of Foxn1 in the nude mouse skin caused higher levels of Ivl and Flg2 expression [14, 29]. High levels of $I v l$ and Flg2 expression in the nude and E14 skin detected in our study can indicate premature differentiation upon the loss of Foxn1 function. A similar observation of premature differentiation of interfollicular epidermal stem cells was made upon loss of function due to Wnt mutation [30]. These deductions are supported by the data showing that Wnt regulates Foxn1 expression in thymus and in the skin [31,32].

Surprisingly, in the uninjured skin (nude and E14) and epidermis (nude), transcriptome analysis revealed upregulation of genes associated with wound healing and its essential inflammation phase (Table 1). Fibronectin 1 $(F n 1)$, which is a component of the provisional matrix of embryos enabling migration and action of cells at the place of injury, is also up-regulated in uninjured nude and E14 skin (Table 1) [33]. Moreover, the skin of nude and E14 samples exhibited a significant elevation in levels of interleukin $1 \alpha(I l-1 A)$ mRNA, a pro-inflammatory interleukin that triggers keratinocyte activation upon injury. Similarly, Il-1 F6 and Il-1 F8, novel players in the Il-1 family signaling system are characteristic for activated (hyperproliferative) keratinocytes and are up-regulated in uninjured skin of nude and E14 mice (Table 1). It should be noted that these two cytokines were shown to influence tissue remodeling (e.g., via regulation of matrix metalloproteinases (Mmps) and fibronectin expression). Additionally, proinflamatory cytokines $I l-18$ and $I l-5$ [34, 35], which are normally rapidly translated in response to injury, are already up-regulated in un-injured skin of nude and E14 (Table 1). Slightly up-regulated levels of proinflammatory cytokines can be beneficial for regenerative resolving of wound healing process, as cytokines attract and stimulate cells (i.e., dermal fibroblasts) at the place of injury. Moreover, the MRL mouse possess increased populations of inflammatory cells during regenerative ear wound closure [36]. On the contrary, the robust inflammatory response in the adult-type repair is consider to be responsible for scar-forming healing usually associated with fibrosis and enhanced deposition of ECM [37]. Therefore, we suggest that fine-tuned inflammation, together with a proper balance between cell migration, proliferation, differentiation, and ECM deposition define whether the final outcome of injury is a chronic/non-healing ulcer, regenerated tissue, or a usual or hypertrophic scar. On the other hand, nude mice are severely immunecompromised, because non-active Foxn1 leads to thymus agenesis and a deficiency of T-cells [38]. Therefore, upregulated transcripts of pro-inflammatory molecules and enhanced kallikreins activity suggest that the skin of nude mice, particularly the epidermal layer (Foxn1 host cells) can act as an immune, compensatory organ $[39,40]$.

It is remarkable that nude and E14 mice displayed elevated expression of genes that have been reported to be induced upon injury in scar healing models. This conclusion compromises ECM (tenascin (Tnc); Additional file 3: Table S3), Fn1 (Table 1), serine proteases (kallikreins, Prss27) cytoskeletal molecules (keratins and keratinsassociated proteins), and proinflammatory cytokines (Table 1). This predisposition to respond immediately, which is common between regenerative nude and E14 mice, is also partially true for the MRL mouse [22]. Therefore, we assume that E14 and nude mice share a transcriptomic milieu that predisposes them to regenerative skin healing when wounding occurs.

Functionally, Foxn 1 is considered to be a transcription factor that activates and stimulates the first stages of keratinocyte differentiation [11]. The analysis of genes in common for nude and E14 revealed down-regulation of a set of genes connected with differentiation and development processes (Table 1). Since nude and E14 do not have an active Foxn1 gene the list of down-regulated genes may contain potential targets of Foxn1. Among these possible targets are the genes coding transcription factors associated with the homeodomain: Hox genes (Hoxb3, Hoxb5, Hoxc6, Hoxd13), extended Hox genes $(G b \times 2)$, Paired domain (Pax1), Paired-like domain (Phox2b, Pitx1), Six/sine homeobox (Six1, Six2) and 
atypical Hox genes (Pknox1) (Table 1). These homeodomain-containing transcriptional regulators specify cell fate during embryonic development and promote embryonic stem cells differentiation [41] and they are known to undergo dynamic repression by Polycomb group (PcG) proteins during development [41].

There is a concept that "Cutaneous wound repair recapitulates embryonic skin development in numerous aspects, in an attempt to restore the integrity of the injured tissue" [33]. Our data supports this, suggesting that the transcriptomic profile of uninjured nude skin resembles that of regenerative uninjured fetuses' skin, that is, a neotenic relationship. Similar retained features of embryonic metabolism were described in adult MRL mice [42]. In our regenerative models, we detected down-regulation of some transcription factors that promote differentiation and block proliferation of epidermal progeny cells (genes repressed by PcG; Table 1). This can lead to an increase in the number of undifferentiated, presumably epidermal stem cells (ESC) [43]. Previously, it was shown that a local population of ESC exerts a positive impact on skin regenerative capacity [44]. Correspondingly, our previous data showed that large populations of nude dermal fibroblasts display stem cell biomarkers compared to wild type B6 dermal fibroblasts [45]. Therefore, we assume that the lack of Foxn1 activity prevents the final stages of differentiation [14] and keeps cells in an immature progenitor-like state $[43,46]$.

\section{Genes enriched in nude skin but not shared with E14 fetuses}

From the total of 1566 genes that are differently regulated between nude vs B6 and not expressed in the E14 skin (Additional file 3: Table S3 and Additional file 4: Table S4), we selected genes that are possibly related to Foxn1 deficiency and provide a transcriptomic signature for regeneration (Table 2). Among these genes, members of the Wnt, Bmp and Notch families were significantly altered (Table 2). It has been shown that genes belonging to these families are responsible for the maintenance of skin homeostasis by playing a role in regulating cell proliferation and differentiation in the skin wound healing process [30, 47-50]. Moreover, it is thought that they take part in regeneration and scarless skin wound healing $[33,51]$.

The analysis of differentially regulated genes revealed that Wnt family genes are generally up-regulated in nude skin. Elevated gene expression in nude skin was observed for Wnt ligands Wisp2, Wnt10a and Wnt11; Wnt mediator $\beta$-catenin $(C t n n b 1)$ and Wnt receptors frizzled $1(F z d 1)$ and frizzled 6 (Fzd6). Concurrently, Wnt pathway inhibitors, dickkopf 1 (Dkk1), frizzledrelated protein $(F r z b)$ and secreted frizzled-related protein 2 (Sfrp2) were down-regulated. Among the Wnt family genes altered in the nude mouse, the expression of Ctnnb1 mRNA was up-regulated in the epidermis but not in the skin (Table 2). In contrast, Wnt7a and catenin $\beta$-like1 (Ctnnbl1) were down-regulated in the skin of nude mice as was $M m p-7$, a component of the Wnt signaling pathway and the target gene for $\beta$-catenin in both nude and E14 skin (Additional file 2: Table S2).

In contrast to the genes of the Wnt family, the genes related to Notch and Bmp are down-regulated in the nude skin (Table 2). The Notch group of genes includes the Notch receptors (Notch2 and 4), Notch ligands (Dll1, 4, and Dlk1) and its transcription factor targets, Hes (5 and 6) and Hey (1 and 2), are down-regulated. Similar to Notch, several genes in the Bmp family are down-regulated in the nude skin, including Bmp ligands (Bmp2 and Bmp4), their receptor (Bmpr1b), and an intracellular component of the Bmp pathway, Smad1 (Table 2).

The next group of genes enriched in nude skin but not shared with E14 is matrix metalloproteinases (Mmps) together with metalloproteinases tissue inhibitors (Timps) (Table 2). The products of these genes are indispensable for skin wound healing process resolution particularly during the final remodeling phase of healing [52] and they are required for the regeneration process [53]. The present analysis confirmed our previous study showing high levels of Mmps in the uninjured and post-injured skin of nude mice $[8-10,45]$. It has been proposed that high levels of Mmps (i.e., Mmp-9) during the regeneration process can prevent scar formation [53]. Our analysis revealed that $M m p-12,-3,-13,-8,-9$, and -2 together with Timp1 are up-regulated in the skin tissues of nude mice (Table 2). The analysis of entire skin tissues as well as enzymatically separated epidermal part of the skin allowed us to detect an unusual pattern of $M m p-9$ expression. Whereas $M m p-9$ expression was upregulated in the skin (similar to other Mmps), it was down-regulated in the epidermis (Table 2).

\section{Changes in genes and protein expression- validation of sequencing data}

To confirm and validate sequencing data we performed qRT-PCR, Western Blot and immunohistochemical detection experiments using independent biological samples from nude, B6, E14 and E18 skin. First, in order to establish and verify the levels of Foxn1 mRNA expression in the examined skin tissues, we performed qRTPCR analysis (Fig. 2a). We detected no Foxn1 transcripts in E14 skin samples, whereas its expression was detected in E18 and adult skin (Fig. 2a). Foxn1 mRNA expression was observed not only in B6 but also in Foxn1 deficient nude mice although at lower levels. The highest levels of Foxn1 transcripts were detected in enzymatically separated epidermis, the host tissue for the Foxn1 expression 
Table 2 Selected group of genes characteristic for nude mice

\begin{tabular}{|c|c|c|c|c|c|}
\hline \multirow[t]{3}{*}{ Gene } & \multirow[t]{3}{*}{ Gene name } & \multicolumn{2}{|c|}{ Epidermis } & \multicolumn{2}{|l|}{ Skin } \\
\hline & & \multicolumn{2}{|c|}{ nude vs B6 } & \multicolumn{2}{|c|}{ nude vs B6 } \\
\hline & & up & down & up & down \\
\hline Wisp2 & WNT1 inducible signaling pathway protein 2 & & & 13.46 & \\
\hline Wnt10a & Wingless related MMTV integration site 10a & & & 4.64 & \\
\hline Wnt11 & Wingless-related MMTV integration site 11 & 3.38 & & 2.48 & \\
\hline Wnt7a & Wingless-related MMTV integration site 7A & & & & 5.63 \\
\hline Fzd1 & Frizzled homolog 1 (Drosophila) & & & 2.18 & \\
\hline Fzd6 & Frizzled homolog 6 (Drosophila) & & & 2.02 & \\
\hline Frzb & Frizzled-related protein & & & & 5.08 \\
\hline Sfrp2 & Secreted frizzled-related protein 2 & & & & 2.38 \\
\hline Ctnnb1 & Catenin (cadherin associated protein), beta 1 & 4.9 & & & \\
\hline Ctnnbl1 & Catenin, beta like 1 & & & & 2.26 \\
\hline Dkk1 & Dickkopf homolog 1 (Xenopus laevis) & & & & 8.22 \\
\hline Dlk1 & Delta-like 1 homolog (Drosophila) & & & & 9.01 \\
\hline DII4 & DII-4 mRNA for Delta-4 & & & & 3.18 \\
\hline$D / 11^{a}$ & Delta-like 1 (Drosophila) & & 2.7 & & 2.33 \\
\hline Notch2 & Notch2 & & 2.36 & & \\
\hline Notch4 & Notch gene homolog 4 (Drosophila) & & & & 2.48 \\
\hline Hes5 & Hairy and enhancer of split 5 (Drosophila) & & & & 10.26 \\
\hline Hes $^{\mathrm{a}}$ & Hairy and enhancer of split 6 (Drosophila) & & & & 8.41 \\
\hline Heyl & $\begin{array}{l}\text { Brain CDNA, clone MNCb-2686, similar to Mus } \\
\text { musculus hairy/enhancer-of-split related with } \\
\text { YRPW motif1 }\end{array}$ & & & & 3.39 \\
\hline Hey2 & HES-related repressor protein 1 HERP1 & & & & 2.39 \\
\hline Bmp2 & Bone morphogenetic protein 2 & & 2.4 & & 3.55 \\
\hline Bmp4 & Bone morphogenetic protein 4 & & 3.23 & & \\
\hline Bmprib & Bone morphogenetic protein receptor, type 1B & & & & 2.75 \\
\hline Smad1 & MAD homolog 1 (Drosophila) & & & & 2.56 \\
\hline Mmp-12 & Matrix metallopeptidase 12 & 3.89 & & 64.36 & \\
\hline Mmp-3 & Matrix metallopeptidase 3 & & & 21.83 & \\
\hline Mmp-13 & Matrix metallopeptidase 13 & & & 5.46 & \\
\hline Mmp-8 & Matrix metallopeptidase 8 & & & 4.71 & \\
\hline Timp 1 & Tissue inhibitor of metalloproteinase 1 & & & 3.58 & \\
\hline Mmp-9 & Matrix metallopeptidase 9 & & 2.22 & 3.28 & \\
\hline Mmp-2 & Matrix metallopeptidase 2 & 2.21 & & 3.02 & \\
\hline
\end{tabular}

${ }^{\mathrm{a}}$ Genes that are down regulated in E14 skin (see Table S2)

(Fig. 2a). Foxn1 mRNA was detected in the nude skin tissue because a single base pair $(G)$ deletion in the exon 3 introduces a frameshift and a premature stop codon causing the encoded protein to terminate upstream of the DNA-binding domain (http://jaxmice.jax.org/strain/ 000819.html).

One of the characteristic features of nude skin is a robust up-regulation of $M m p-12,-3,-13,-8,-9$, and -2 (Table 2). qRT-PCR validation (Fig. $2 \mathrm{~b}$ and c) confirmed that $M m p-13$ and $M m p-9$ are up-regulated in the skin of nude mice as shown by RNA-seq analysis (Table 2). However, RNA-seq results showed a discrepancy in Mmp-9 expression between the whole skin samples and the enzymatically separated epidermis. In contrast to the skin, the epidermis from the nude skin showed significant down-regulation of $M m p-9$ expression (Table 2). qRT-PCR examination of an independent set of samples from nude and B6 confirmed sequencing RNA-seq results indicating differences between $\mathrm{Mmp}$-9 expression in epidermis (Fig. 2c; $p<0.001$ ). Since the expression 


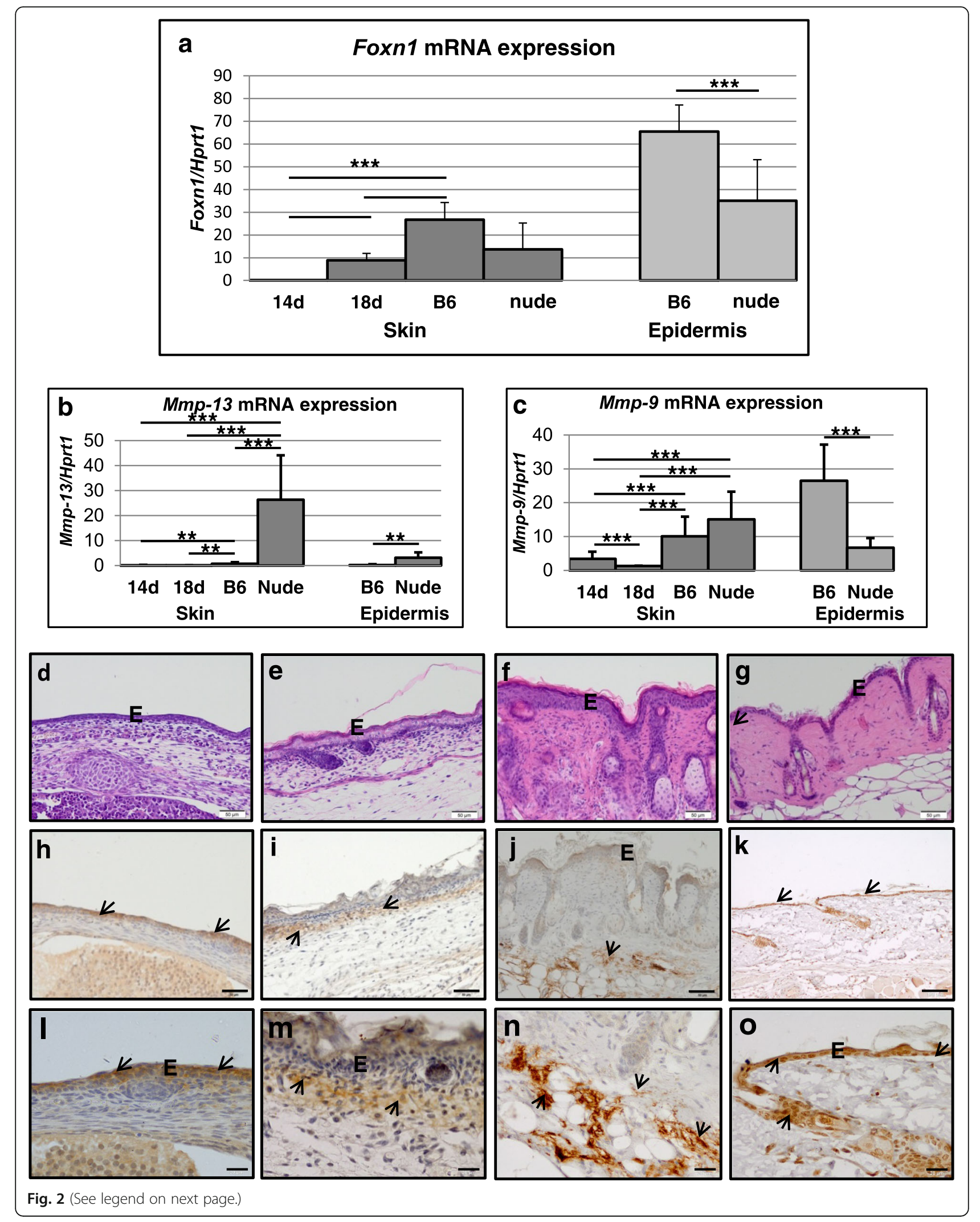


(See figure on previous page.)

Fig. 2 Validation of sequencing data by qRT-PCR for Foxn1 (a), Mmp-13 (b) and Mmp-9 (c). Histological (d-g), immunohistochemical (h-o) analyses of skin

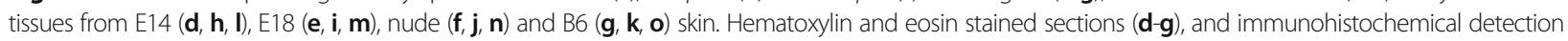
of Mmp-9 protein expression (h-o). Figure l-o are the higher magnifications of figures $\mathbf{h}-\mathrm{k}$. Arrows indicate positive reaction for Mmp-9 in epidermis: E14 (h I) and B6 (k, o); dermis: E18 (i, $\mathbf{m})$ and subcutenous tissues in nude $(\mathbf{j}, \mathbf{n})$. Immunohistochemical sections $(\mathbf{h}-\mathbf{o})$ were counterstained with hematoxylin. E - epidermis. Scale bar $=50 \mu \mathrm{m}(\mathbf{d}-\mathbf{j}), 100 \mu \mathrm{m}(\mathbf{k}), 20 \mu \mathrm{m}(\mathbf{l}-\mathbf{o})$

and regulation of Mmp-9 seems to be of particular importance in skin we performed immunohistochemical detection of Mmp-9 protein expression (Fig. 2h-o). Whereas the Mmp-9 protein in the nude skin tissue was localized to subcutaneous tissues and dermis with no expression in the epidermis (Fig. $2 \mathrm{j}$ and $\mathrm{n}$ - arrows), B6 skin showed strong Mmp-9 expression in the epidermis (Fig. 2k and o - arrows). Skin samples from E14 (Fig. 2h and $\mathrm{l}$ ) and E18 (Fig. 2i and $\mathrm{m}$ ) show Mmp-9 protein expression in the epidermis (E14) and dermis (E18). The high levels of Mmp-9 expression in nude dermis (Fig. 2c, $\mathrm{j}$ and $\mathrm{n}$ ) could be partially explained by the differences in dermal fibroblasts phenotype between nude and wild type mice [10]. Our previous studies showed the ability of nude dermal fibroblasts to synthesize higher than wild type mRNA and protein levels of Mmp-9 [10]. The transcriptomic data for $I v l$ expression showed an increase in $I v l$ transcript levels in E14 skin and in the nude skin and epidermis (Table 1). Western Blot (Fig. 3a-b) and immunohistology (3c-f) analyses showed higher levels of Ivl protein in E18 than E14 (Fig. 3a-b; compare Fig. 3c and d). Moreover, we observed strong Ivl immunoreactivity in the entire epidermis of nude (Fig. 3e) but only at outer layer of B6 (Fig. 3f) epidermis.

Foxn 1 deficiency in epidermis affects dermal part of the skin Although the mechanism of Foxn1 action is largely unknown, recent data point to Fgf2 as a mediator of Foxn1 function in the epidermis [54]. The present analysis showing the differences in gene expression between B6 and nude mice in epidermal and dermal skin parts (Tables 1 and 2, Additional file 1: Table S1, Additional file 2: Table S2, Additional file 3: Table S3, Additional file 4: Table S4) may indicate that Foxn1 elicits its action not only within the epidermis but it participates in dermal cell functionality. Moreover, our previous data clearly showed phenotypic differences between the nude and B6 dermal fibroblasts, indicating a population of immature (stem cell-like) dermal fibroblasts in the nude dermis [45]. Furthermore, the nude skin, as well as the nude dermal fibroblasts, expressed higher levels of Mmps than in B6 mice $[10,45]$. Consequently, we reasoned that Foxn1 expression in the epidermis may affect dermal fibroblasts via Fgf2. To evaluate this concept, we measured the effect of Fgf2 on Mmps expression in the dermal fibroblasts from nude and B6 mice. Isolated and cultured cells were treated for $24 \mathrm{~h}$ with increasing doses of Fgf2 (0.1, 1, 10, 100, 1000 ng/ml; Fig. 4). The analysis of $M m p s$ mRNA expression showed that Fgf2 increased $M m p-3,-9$ and -13 expression in both nude and B6 dermal fibroblasts but had no effect on $\mathrm{Mmp}$-2 expression. Interestingly, the stimulatory effect of Fgf2 was profound for the nude dermal fibroblasts. The increase in $\mathrm{Mmp}$ $13,-3$ and -9 expression in nude dermal fibroblasts was already observed at a lower dose $(0.1 \mathrm{ng} / \mathrm{ml})$ of Fgf2 to achieve the highest impact on $M m p$ expression at $10 \mathrm{ng} /$ $\mathrm{ml}$ (Fig. $4 \mathrm{a}, \mathrm{b}$ and $\mathrm{c}$ ). The profound effect of Fgf2 on Mmp-9 expression in the dermal fibroblasts from nude mice was confirmed by Western Blot analysis of protein isolates from nude and B6 dermal fibroblasts (Fig. 4e). Collectively, we propose that B6 dermal fibroblasts achieve the adult/mature state through the first wave of Foxn1 expression during embryonic development, whereas nude dermal fibroblasts, which respond much more strongly to Fgf2 stimulation, are sustained in a fetal (neoteny) stage. These data, together with our previous reports, support the concept that Foxn1 activity is an essential condition to establish the adult skin phenotype. Further on, Foxn1 as a key component of skin maturation, could be responsible for scar-forming healing and its deficiency sustains skin in neoteny, which can lead to scar-free skin healing as it is observed in E14 and nude mice.

\section{Conclusions}

This is the first report showing that two models of skin regeneration, nude mice and E14 fetuses, share similarities that comprise expression patterns associated with genes having specific biological and cellular functions (terms). The genes associated with these functional terms may be considered as a signature for regeneration. Moreover, based on the down-regulation of transcription factors, which promote differentiation instead of proliferation (e.g., during embryo development), we provide a theory that the retarded development of the skin of nude mice leads to the retention of a large population of immature, progenitor-like stem cells. Foxn1 appears to be a pivotal control element of the developmental program and skin maturation. Therefore, nude mice may be considered as a unique example of neoteny among mammals. In addition, nude and E14 mice can be viewed as genetically programmed to immediately respond to injury, since elevated levels of critical transcripts are already in place. The consequences of Foxn1 deficiency 

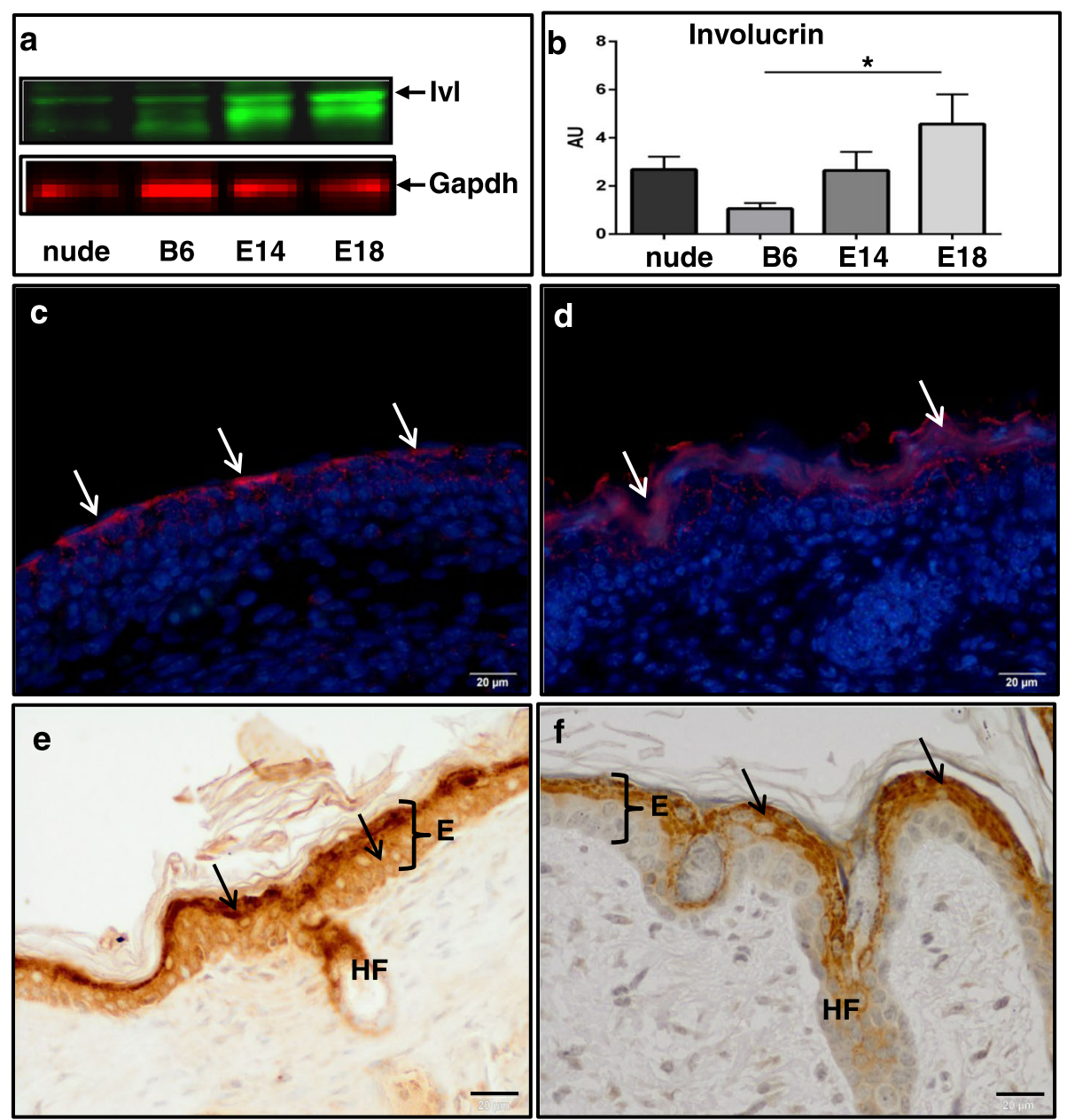

Fig. 3 Involucrin protein expression in nude, B6, E14 and E18 skin samples. Representative Western Blots (a), densitometric analysis (b) and immunodetection (c-f) of involucrin protein expression in E14 (c), E18 (d), nude (e), B6 (f) skin samples. Arrows indicate positive reaction for involucrin (c-f). Immunohistochemical sections (e-f) were counterstained with hematoxylin. E - epidermis, HF - hair follicles. Scale bar = 20 $\mu m$

suggest an interplay of Foxn1 with Wnt, Bmp and Notch signaling. Moreover, Foxn1 appears to be a regulator of Mmp-9 expression in the skin.

\section{Methods}

\section{Animals and sample collection}

The experimental animal procedures performed in these studies have been approved by the Institutional Animal Care and Use Committee at the Pennington Biomedical Research Center and Institutional Animal Care and Use Committee at the University of Warmia and Mazury.

C57BL/6J (B6) and B6.Cg-Foxn1 nu (nude) mice were purchased from The Jackson Laboratory, ME. Twelveweek-old female and male B6 mice were caged together and the presence of a vaginal plug indicated possible pregnancy and the embryonic age of fetus was designated as gestational day 0.5 (E1). Embryos were collected at embryonic days E14 and E18. Pregnant mice were anesthetized by intraperitoneal injections of ketamine
(45 mg/kg) and xylazine (3 mg/kg). An abdominal midline incision was made to expose the uterus. The fetuses were removed from the uterine cavity. Under the dissecting microscopy (10 $\times$ magnification, Zeiss, Germany), individual fetuses were immediately killed by decapitation and the full-thickness dorsal skin of fetus was excised with microscissors. The skin samples were immediately snap-frozen in liquid nitrogen for subsequent RNA and /or protein isolation or fixed in: 4\% paraformaldehyde (PFA) (SigmaAldrich, St. Louis, MO, USA) or 10\% formalin for histological analyses. The pregnant mice were euthanized after the surgery was completed.

Six-week-old female C57BL/6J (B6, $n=10)$ and B6.CgFoxn1 nu (nude, $n=10$ ) mice coming directly from The Jackson Laboratory (Bar Harbor, ME, USA) were used to isolate skin tissues from adult animals. Wild type mice were shaved the day before tissue collections. Animals (B6: $n=6$, nude: $n=6$ ) were sacrificed and full-thickness back skin samples were dissected and immediately 

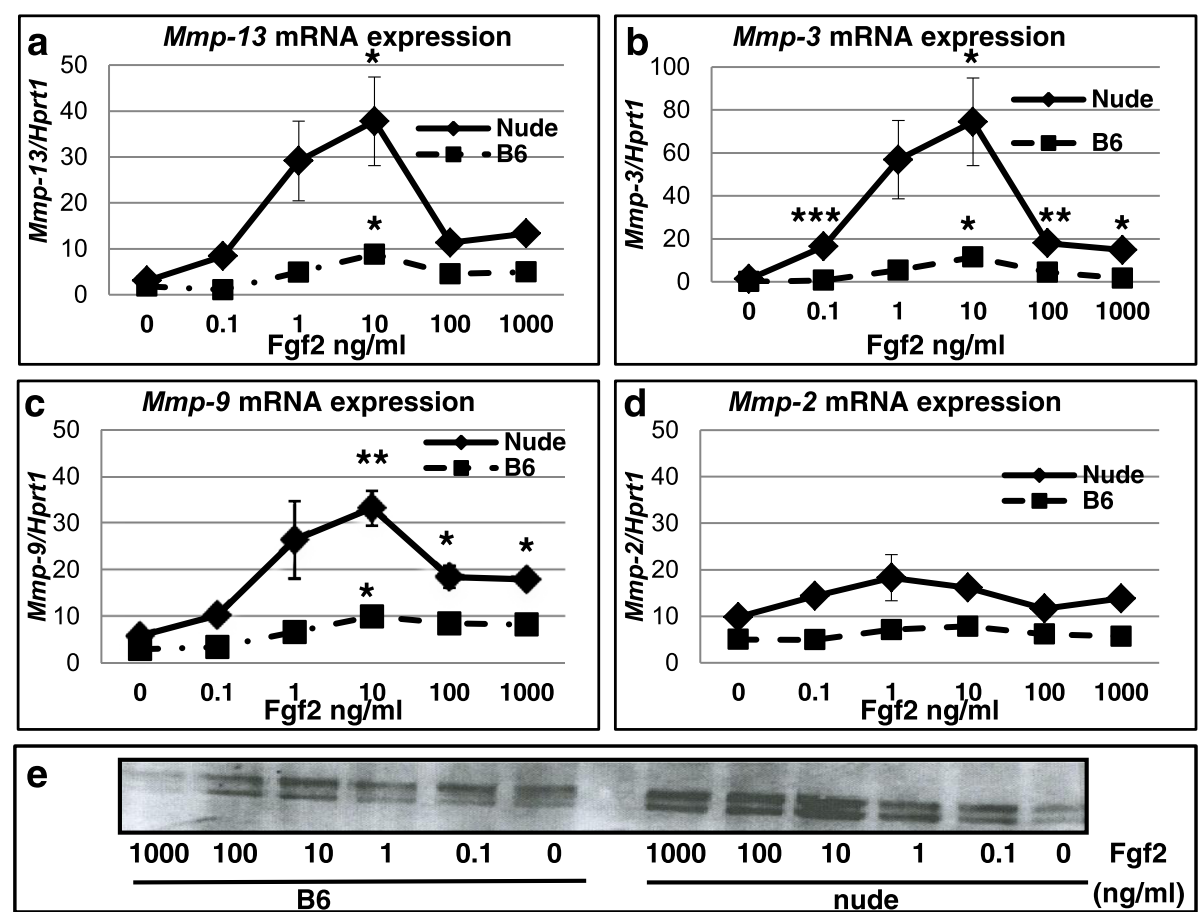

Fig. 4 In vitro analysis of Fgf2 effects on Mmp-13 (a), Mmp-3 (b), Mmp-9 (c, e) and Mmp-2 (d) expression in dermal fibroblasts from nude and B6 mice. Quantitative RT-PCR for Mmp-13 (a), Mmp-3 (b), Mmp-9 (c) and Mmp-2 (d) mRNA expression and Western blot for Mmp-9 (e) protein are presented

transferred into liquid nitrogen for subsequent RNA extraction or fixed in: 4\% PFA (Sigma-Aldrich) or 10\% formalin for histological analysis. Four animals per group (B6 $n=4$, nude $n=4$ ) were used for epidermis isolation. Dissected skin was submerged in HBSS (Sigma-Aldrich) with primocin (InvivoGen, San Diego, CA, USA) followed by overnight incubation in dispase (Life Technologies) solution at $4{ }^{\circ} \mathrm{C}$ on a rocking platform. The next day, the epidermis was collected, washed in PBS and transferred to Trizol reagent (Invitrogen, Carlsbad, CA, USA) for RNA isolation.

\section{Library generation \& sequencing}

Skin samples of E14, E18, nude and B6 consisted of $n=6$ per group. Epidermal samples for nude and B6 were equal $n=4$ per group. Total RNA from each sample was isolated using Trizol reagent as recommended by the supplier. RNA was further purified by using RNeasy and RNaseFree DNase kits (Qiagen, Valencia, CA, USA). RNA integrity was checked by $1 \%(\mathrm{~m} / \mathrm{v})$ agarose gel electrophoresis. The quality of total RNA was analyzed using an Agilent Bioanalyzer and all samples reached a quality score (RIN) above 7. Total RNA samples were prepared for sequencing using the SOLiD ${ }^{\text {tm }}$ SAGE Kit with Barcoding Adaptor Module Kit (Life Technologies) using 500 ng input according to the manufacturer's protocol. Emulsion PCR and SOLiD sequencing, SAGE-sequencing of 35 base pair tags, 30 base pairs in a single direction, were performed according to the manufacturer's instructions for the SOLiD $^{\mathrm{Tw}} 3$ System (Life Technologies). SAGE-seq data does not require the transcript abundance calculation based upon transcript length or identification of isoforms since each transcript is mapped by a single $3^{\prime}$ tag. It is important to emphasize, that SAGE sequencing was performed on individual but not pooled RNA samples (total $n=32$; including: E14 $n=6$, E18 $n=6$, nude $n=6$, B6 $n=$ 6 per skin and nude $n=4, B 6=4$ per epidermis).

The number of reads mapping to a unique transcript obtained from the sequencing the DNA fragments were as follow: epidermis B6 18,520,100; epidermis nude 12,689,199; skin E14 26,735,763; skin E18 21,730,454; skin nude 22,873,269 and skin B6 26,406,841.

Erroneous sequence tags were eliminated using quality values before alignment where the quality value ' $\mathrm{q}$ ' corresponds to the failing probability of $p=10^{\wedge}(-\mathrm{q} / 10)$. Tag counts were included if the quality value of each base call in the tag was greater than or equal to 10 .

\section{Data analysis-SAGE-seq dataset}

Sequenced fragments were aligned to the mouse NCBI37/ mm9 SAGE reference sequence using SOLiD ${ }^{\mathrm{mm}}$ SAGE $^{\mathrm{m}} \mathrm{v} 1.10$ software (Life Technologies). Raw counts were used as the input for differential expression analysis using GeneSifter, Geospiza, Inc. Libraries were normalized using the geometric mean. Reads with up to 1 mismatch which mapped uniquely to a single transcript were counted. Fold changes 
of expression at the gene level were calculated. For the preliminary selection, genes met a fold-change in expression of $>$ or $=1.5$ between experimental groups and a $p$-value or Benjamini-Hochberg adjusted $p$-value of 0.05 . The obtained gene data set were deposited in the Gene Expression Omnibus (GEO) repository: GSE71619.

For further analysis we used genes considered as a differentially expressed based on: 1) A greater than or equal to two fold change in expression; 2) The $p$ value was less than or equal to 0.05 . Functional gene annotation was performed with DAVID bioinformatics platform 6.8 provided by the National Institute of Allergy and Infectious Diseases (https://david.ncifcrf.gov). [55, 56]. The statistical significance of gene set enrichment was determined using the modified Fisher's exact test. BenjaminiHochberg correction procedure for multiple comparisons using a $p$-value threshold of $<0.05$ was carried out for the final selection of ontological terms.

\section{Real-time PCR and western blot analyses}

Sample preparations of total RNA for qRT-PCR and protein isolation for Western Blot analyses were performed as described previously [10] To measure the levels of Foxn1, Mmp-9, Mmp-13, Hprt1 mRNA expression, single tube TaqMan $^{\oplus}$ Gene Expression Assays (Life Technologies) were used. Each run included a standard curve based on aliquots of RNA pooled from different skin tissue samples. All samples were analyzed in duplicates. mRNA expression levels were normalized to the reference gene - Hprt1 (hypoxanthine phosphoribosyl transferase 1) and multiplied by 10 .

Primary antibodies used in Western Blot analysis were rabbit anti-involucrin (Covance; Princeton, NJ, USA), rabbit anti-Mmp-9 (Millipore, Billerica, MA, USA) and mouse anti-Gapdh (AbCam, Cambridge, UK). As secondary antibodies IRDye800TM and Cy5.5 (Rockland, Limerick, PA, USA) were used. Bands were visualized using the Odyssey imaging system (LI-COR Bioscience) according to the manufacturer's protocol. Densitometric protein analysis was performed as previously described [12].

\section{Histology and immunohistochemistry}

Formalin fixed, paraffin embedded and sectioned $(5 \mu \mathrm{m})$ skin tissues were used for histological analysis (H\&E staining) and immunohistological detection of Mmp-9 and involucrin expression. For immunohistochemistry skin sections were deparaffinized in xylene (Sigma-Aldrich), treated with $0.75 \%$ glycine (Sigma-Aldrich) for 30 min to block free aldehyde groups and with $3 \% \mathrm{H}_{2} \mathrm{O}_{2}$ (Sigma-Aldrich) for 5 min to block endogenous peroxidases. Slides were blocked in $10 \%$ normal horse serum (Vector Laboratories, Burlingame, CA, USA) for $1 \mathrm{~h}$ at RT. Primary antibodies: rabbit anti-involucrin (1:1500, Covance) or rabbit anti-Mmp-9 (1:100, Millipore) were applied (o/ $\left.\mathrm{n} ; 4{ }^{\circ} \mathrm{C}\right)$. Antibody binding was detected with the
ABC complex (Vectastain ABC kit from Vector Laboratories). Peroxidase activity was revealed using 3,3'-diaminobenzidine tetrahydrochloride (Sigma- Aldrich) as a substrate. Two types of controls were performed: (a) the primary antibody was omitted during the procedure; (b) the primary antibody was substituted with nonspecific immunoglobulin G (IgG) during the immunostaining procedure. Tissue sections were mounted undercoverslips with DPX (Merck; Kenilworth, NJ, USA).

\section{Immunofluorescence}

The immunofluorescence procedure was based on a published protocols $[12,57]$ with modifications. Skin tissues for immunofluorescent detection of involucrin were fixed for $2 \mathrm{~h}$ in $4 \%$ paraformaldehyde (Sigma-Aldrich) in $0.1 \mathrm{M}$ phosphate buffer (PB). Fixed tissues were stored in $18 \%$ sucrose (Sigma-Aldrich) in PB with $0.01 \%$ sodium azide (Sigma-Aldrich). Cryostat sections $(8 \mu \mathrm{m})$ were blocked in $10 \%$ normal horse serum (Vector Laboratories) in $0,1 \%$ BSA in PB for $1 \mathrm{~h}$ at RT and incubated with rabbit antiinvolucrin (1:1500; Covance) antibodies o/n at $4{ }^{\circ} \mathrm{C}$. Tissue sections were subsequently incubated with Alexa Fluor 594 (Life Technologies) for $1 \mathrm{~h}$ at RT. Slides were mounted under coverslips using ProLong ${ }^{\oplus}$ Gold Antifade Mountant with DAPI (Life Technologies).

Sections were visualized and photographed with an Olympus microscope (BX43) equipped with an Olympus digital camera (XC50) and analyzed with CellSens Dimension 1 Software (Olympus Soft Imaging Solutions $\mathrm{GmbH}$ ).

\section{Additional files}

Additional file 1: Table S1. Genes in common for E14 and nude skin that are up-regulated for nude vs B6 and up-regulated for E14 vs E18. (DOCX $34 \mathrm{~kb}$ )

Additional file 2: Table S2. Genes in common for E14 and nude skin that are down-regulated for nude vs B6 and down-regulated for E14 vs E18. (DOCX $78 \mathrm{~kb}$ )

Additional file 3: Table S3. Genes that are up-regulated in nude (vs B6) skin and epidermis, and not in common with E14 (vs E18). (DOCX 103 kb)

Additional file 4: Table S4. Genes that are down-regulated in nude (vs B6) skin and epidermis, and not in common with E14 (vs E18). (DOCX 101 kb)

\section{Abbreviations}

B6: C57BL/6J; Bmp: Bone morphogenetic proteins; Ctnnb1: $\beta$-catenin; Ctnnbl1: Catenin $\beta$-like1; Dkk1: Dickkopf 1; E14: Mouse fetuses at 14 day of embryonic development; E18: Mouse fetuses at 18 day of embryonic development; ESC: Epidermal stem cells; Fgf2: Fibroblasts growth factor 2 (basic fibroblasts growth factor); Flg2: Filaggrin; Fn1: Fibronectin 1; Foxn1: Forkhead box N1; Frzb: Frizzled-related protein; Fzd: Frizzled 1; II: Interleukin; Ivl: Involucrin; Klk: Kallikrein-related peptidases; Krt: Keratin; Mmp: Matrix metalloproteinases; nude: B6.Cg-Foxn1 nu; PcG: Polycomb group proteins; PFA: Paraformaldehyde; Prss27: Protease serine 27; qRTPCR: Quantitative reverse transcriptase real-time PCR; Rptn: Repetin; Sfrp2: Secreted frizzled-related protein 2; Sprr2d: Small proline-rich protein; Timp: Tissue inhibitors of matrix metalloproteinases; Wnt: Wingless 


\section{Acknowledgements}

We are grateful to Susan Newman, Richard Carmouche and Michael Salbaum for sequencing the RNA samples with the Applied Biosystems SOLiD Next Generation sequencing platform, management of the data and preparing the data for transmission to GEO.

\section{Funding}

The research in the Gawronska-Kozak laboratory is supported by grant from the National Science Centre of Poland (NCN, Poland) DEC-2012/05/B/NZ5/ 01537.

This project used the Genomics Core Facility at the Pennington Biomedical Research Center, LA, USA, that is supported in part by COBRE (NIH 8 P20 GM103528-07) and NORC (NIH 1P30-DK072476) center grants from the National Institutes of Health.

\section{Availability of data and materials}

The data set supporting the results of this article is available in the Gene Expression Omnibus (GEO) repository: GSE71619; http:// www.ncbi.nlm.nih.gov/geo/query/acc.cgi?acc=GSE71619.

\section{Authors' contributions}

AKP - collection, interpretation and assembly of data, manuscript writing, final approval of manuscript; MK - Western Blot and qRT-PCR analysis, interpretation of data, final approval of manuscript; LPK - design of the study, interpretation of data, final approval of manuscript; PS - analysis and interpretation of data, final approval of manuscript, AG - histological and immunohistochemical analysis, final approval of manuscript; BGK-conception and design of the study, collection, analysis and interpretation of data, manuscript writing, final approval of manuscript.

\section{Competing interests}

The authors declare that they have no competing interests.

\section{Consent for publication}

Not applicable.

\section{Ethics approval and consent to participate}

The experimental animal procedures performed in these studies have been approved by the Institutional Animal Care and Use Committee at the Pennington Biomedical Research Center, Baton Rouge, LA, USA and Institutional Animal Care and Use Committee at the University of Warmia and Mazury, Olsztyn, Poland.

\section{Author details}

${ }^{1}$ Institute of Animal Reproduction and Food Research, Polish Academy of Sciences, ul. Tuwima 10, 10-748 Olsztyn, Poland. ${ }^{2}$ Department of Molecular Biotechnology and Microbiology, Gdansk University of Technology, ul. G. Narutowicza 11/12, 80-233 Gdansk, Poland.

\section{Received: 25 November 2015 Accepted: 9 December 2016}

\section{Published online: 09 January 2017}

\section{References}

1. Levesque M, Villiard E, Roy S. Skin wound healing in axolotls: a scarless process. J Exp Zool B Mol Dev Evol. 2010;314(8):684-97.

2. Seifert AW, Monaghan JR, Voss SR, Maden M. Skin regeneration in adult axolotls: a blueprint for scar-free healing in vertebrates. PLoS One. 2012;7(4):e32875.

3. Yokoyama H, Maruoka T, Aruga A, Amano T, Ohgo S, Shiroishi T, Tamura K. Prx-1 expression in Xenopus laevis scarless skin-wound healing and its resemblance to epimorphic regeneration. J Invest Dermatol. 2011;131(12): 2477-85.

4. Rowlatt U. Cleft lip and palate associated with amniotic band limb amputations in a 20 week human fetus. Cleft Palate J. 1979;16(2):206-9.

5. Ihara S, Motobayashi Y, Nagao E, Kistler A. Ontogenetic transition of wound healing pattern in rat skin occurring at the fetal stage. Development. 1990; 110(3):671-80.

6. Lorenz HP, Longaker MT, Perkocha LA, Jennings RW, Harrison MR, Adzick NS. Scarless wound repair: a human fetal skin model. Development. 1992;114(1):253-9.

7. Bellavia G, Fasanaro P, Melchionna R, Capogrossi MC, Napolitano M. Transcriptional control of skin reepithelialization. J Dermatol Sci. 2014;73(1):3-9.
8. Gawronska-Kozak B, Bogacki M, Rim JS, Monroe WT, Manuel JA. Scarless skin repair in immunodeficient mice. Wound Repair Regen. 2006;14:265-76.

9. Manuel JA, Gawronska-Kozak B. Matrix metalloproteinase 9 (MMP-9) is upregulated during scarless wound healing in athymic nude mice. Matrix Biol. 2006;25:505-14.

10. Gawronska-Kozak B. Scarless skin wound healing in FOXN1 deficient (nude) mice is associated with distinctive matrix metalloproteinase expression. Matrix Biol. 2011;30(4):290-300.

11. Lee $D$, Prowse DM, Brissette JL. Association between mouse nude gene expression and the initiation of epithelial terminal differentiation. Dev Biol. 1999;208(2):362-74.

12. Gawronska-Kozak B, Grabowska A, Kur-Piotrowska A, Kopcewicz M. Foxn1 Transcription Factor Regulates Wound Healing of Skin through Promoting Epithelial-Mesenchymal Transition. PLoS One. 2016;11(3):e0150635.

13. Hu MS, Januszyk M, Hong WX, Walmsley GG, Zielins ER, Atashroo DA, Maan ZN, McArdle A, Takanishi Jr DM, Gurtner GC, et al. Gene expression in fetal murine keratinocytes and fibroblasts. J Surg Res. 2014;190(1):344-57.

14. Janes SM, Ofstad TA, Campbell DH, Watt FM, Prowse DM. Transient activation of FOXN1 in keratinocytes induces a transcriptional programme that promotes terminal differentiation: contrasting roles of FOXN1 and Akt. J Cell Sci. 2004;117(Pt 18):4157-68.

15. Mercer SE, Cheng CH, Atkinson DL, Krcmery J, Guzman CE, Kent DT, Zukor K, Marx KA, Odelberg SJ, Simon HG. Multi-tissue microarray analysis identifies a molecular signature of regeneration. PLoS One. 2012;7(12):e52375.

16. Sousounis K, Michel CS, Bruckskotten M, Maki N, Borchardt T, Braun T, Looso $M$, Tsonis PA. A microarray analysis of gene expression patterns during early phases of newt lens regeneration. Mol Vis. 2013;19:135-45.

17. Heydemann A. The super super-healing MRL mouse strain. Front Biol (Beijing). 2012;7(6):522-38.

18. Schlake T, Boehm T. Expression domains in the skin of genes affected by the nude mutation and identified by gene expression profiling. Mech Dev. 2001;109(2):419-22.

19. Kishibe M, Bando $Y$, Tanaka T, Ishida-Yamamoto A, lizuka H, Yoshida S. Kallikrein-related peptidase 8-dependent skin wound healing is associated with upregulation of kallikrein-related peptidase 6 and PAR2. J Invest Dermatol. 2012;132(6):1717-24.

20. Li W, Danilenko DM, Bunting S, Ganesan R, Sa S, Ferrando R, Wu TD, Kolumam GA, Ouyang W, Kirchhofer D. The serine protease marapsin is expressed in stratified squamous epithelia and is up-regulated in the hyperproliferative epidermis of psoriasis and regenerating wounds. J Biol Chem. 2009;284(1):218-28

21. Freedberg $\mathbf{I M}$, Tomic-Canic M, Komine M, Blumenberg M. Keratins and the keratinocyte activation cycle. J Invest Dermatol. 2001;116(5):633-40.

22. Cheng CH, Leferovich J, Zhang XM, Bedelbaeva K, Gourevitch D, Hatcher CJ, Basson CT, Heber-Katz E, Marx KA. Keratin gene expression profiles after digit amputation in C57BL/6 vs. regenerative MRL mice imply an early regenerative keratinocyte activated-like state. Physiol Genomics. 2013:45(11):409-21.

23. Mazzalupo S, Wong P, Martin P, Coulombe PA. Role for keratins 6 and 17 during wound closure in embryonic mouse skin. Dev Dyn. 2003;226(2):356-65.

24. Seifert AW, Kiama SG, Seifert MG, Goheen JR, Palmer TM, Maden M. Skin shedding and tissue regeneration in African spiny mice (Acomys). Nature. 2012:489(7417):561-5.

25. Ishida-Yamamoto A, Kartasova T, Matsuo S, Kuroki T, lizuka H. Involucrin and SPRR are synthesized sequentially in differentiating cultured epidermal cells. J Invest Dermatol. 1997:108(1):12-6.

26. Marshall D, Hardman MJ, Nield KM, Byrne C. Differentially expressed late constituents of the epidermal cornified envelope. Proc Natl Acad Sci U S A. 2001;98(23):13031-6

27. Baxter RM, Brissette JL. Role of the nude gene in epithelial terminal differentiation. J Invest Dermatol. 2002;118(2):303-9.

28. Li J, Baxter RM, Weiner L, Goetinck PF, Calautti E, Brissette JL. Foxn1 promotes keratinocyte differentiation by regulating the activity of protein kinase C. Differentiation. 2007;75(8):694-701.

29. Brissette JL, Li J, Kamimura J, Lee D, Dotto GP. The product of the mouse nude locus, Whn, regulates the balance between epithelial cell growth and differentiation. Genes Dev. 1996;10(17):2212-21.

30. Lim X, Tan SH, Koh WL, Chau RM, Yan KS, Kuo CJ, van Amerongen R, Klein AM, Nusse R. Interfollicular epidermal stem cells self-renew via autocrine Wnt signaling. Science. 2013;342(6163):1226-30.

31. Balciunaite G, Keller MP, Balciunaite E, Piali L, Zuklys S, Mathieu YD, Gill J Boyd R, Sussman DJ, Hollander GA. Wht glycoproteins regulate the 
expression of FoxN1, the gene defective in nude mice. Nat Immunol. 2002; 3(11):1102-8.

32. Hu B, Lefort K, Qiu W, Nguyen B-C, Rajaram RD, Castillo E, He F, Chen Y, Angel $P$, Brisken $C$, et al. Control of hair follicle cell fate by underlying mesenchyme through a CSL-Wnt5a-FoxN1 regulatory axis. Genes Dev. 2010; 24(14):1519-32.

33. Bielefeld KA, Amini-Nik S, Alman BA. Cutaneous wound healing: recruiting developmental pathways for regeneration. Cell Mol Life Sci. 2013;70(12): 2059-81.

34. Leitch VD, Strudwick XL, Matthaei KI, Dent LA, Cowin AJ. IL-5-overexpressing mice exhibit eosinophilia and altered wound healing through mechanisms involving prolonged inflammation. Immunol Cell Biol. 2009;87(2):131-40.

35. Kampfer H, Muhl H, Manderscheid M, Kalina U, Kauschat D, Pfeilschifter J, Frank S. Regulation of interleukin-18 (IL-18) expression in keratinocytes (HaCaT): implications for early wound healing. Eur Cytokine Netw. 2000; 11(4):626-33.

36. Gourevitch D, Kossenkov AV, Zhang Y, Clark L, Chang C, Showe LC, HeberKatz E. Inflammation and Its Correlates in Regenerative Wound Healing: An Alternate Perspective. Adv Wound Care (New Rochelle). 2014;3(9):592-603.

37. Martin P, Leibovich SJ. Inflammatory cells during wound repair: the good, the bad and the ugly. Trends Cell Biol. 2005;15(11):599-607.

38. Mecklenburg L, Tychsen B, Paus R. Learning from nudity: lessons from the nude phenotype. Exp Dermatol. 2005;14(11):797-810.

39. Eissa A, Amodeo V, Smith CR, Diamandis EP. Kallikrein-related peptidase-8 (KLK8) is an active serine protease in human epidermis and sweat and is involved in a skin barrier proteolytic cascade. J Biol Chem. 2011;286(1):687-706.

40. Eissa A, Diamandis EP. Human tissue kallikreins as promiscuous modulators of homeostatic skin barrier functions. Biol Chem. 2008;389(6):669-80.

41. Boyer LA, Plath K, Zeitlinger J, Brambrink T, Medeiros LA, Lee TI, Levine SS, Wernig M, Tajonar A, Ray MK, et al. Polycomb complexes repress developmental regulators in murine embryonic stem cells. Nature. 2006; 441(7091):349-53.

42. Naviaux RK, Le TP, Bedelbaeva K, Leferovich J, Gourevitch D, Sachadyn P, Zhang XM, Clark L, Heber-Katz E. Retained features of embryonic metabolism in the adult MRL mouse. Mol Genet Metab. 2009;96(3):133-44.

43. Bohr S, Patel SJ, Vasko R, Shen K, Huang G, Yarmush ML, Berthiaume F. Highly upregulated Lhx2 in the Foxn1-/- nude mouse phenotype reflects a dysregulated and expanded epidermal stem cell niche. PLoS One. 2013;8(5):e64223.

44. Pastar I, Stojadinovic O, Yin NC, Ramirez H, Nusbaum AG, Sawaya A, Patel SB, Khalid L, Isseroff RR, Tomic-Canic M. Epithelialization in Wound Healing: A Comprehensive Review. Adv Wound Care (New Rochelle). 2014;3(7):445-64.

45. Gawronska-Kozak B, Kirk-Ballard H. Cyclosporin A reduces matrix metalloproteinases and collagen expression in dermal fibroblasts from regenerative FOXN1 deficient (nude) mice. Fibrogenesis Tissue Repair. 2013;6(1):7.

46. Boehm T, Swann JB. Thymus involution and regeneration: two sides of the same coin? Nat Rev Immunol. 2013;13(11):831-8.

47. Whyte JL, Smith AA, Liu B, Manzano WR, Evans ND, Dhamdhere GR, Fang $M Y$, Chang HY, Oro AE, Helms JA. Augmenting endogenous Wnt signaling improves skin wound healing. PLoS One. 2013;8(10):e76883.

48. Zhu XJ, Liu Y, Dai ZM, Zhang X, Yang X, Li Y, Qiu M, Fu J, Hsu W, Chen Y, et al. BMP-FGF signaling axis mediates Wnt-induced epidermal stratification in developing mammalian skin. PLoS Genet. 2014;10(10):e1004687.

49. Okuyama R, Tagami H, Aiba S. Notch signaling: its role in epidermal homeostasis and in the pathogenesis of skin diseases. J Dermatol Sci. 2008;49(3):187-94.

50. Lewis CJ, Mardaryev AN, Poterlowicz K, Sharova TY, Aziz A, Sharpe DT, Botchkareva NV, Sharov AA. Bone morphogenetic protein signaling suppresses wound-induced skin repair by inhibiting keratinocyte proliferation and migration. J Invest Dermatol. 2014;134(3):827-37.

51. Wehner D, Cizelsky W, Vasudevaro MD, Ozhan G, Haase C, Kagermeier-Schenk B, Roder A, Dorsky Rl, Moro E, Argenton F, et al. Wnt/beta-catenin signaling defines organizing centers that orchestrate growth and differentiation of the regenerating zebrafish caudal fin. Cell Rep. 2014;6(3):467-81.

52. Gill SE, Parks WC. Metalloproteinases and their inhibitors: regulators of wound healing. Int J Biochem Cell Biol. 2008;40(6-7):1334-47.

53. Vinarsky V, Atkinson DL, Stevenson TJ, Keating MT, Odelberg SJ. Normal newt limb regeneration requires matrix metalloproteinase function. Dev Biol. 2005;279(1):86-98

54. Weiner L, Han R, Scicchitano BM, Li J, Hasegawa K, Grossi M, Lee D, Brissette JL. Dedicated epithelial recipient cells determine pigmentation patterns. Cell. 2007;130(5):932-42.
55. da Huang W, Sherman BT, Lempicki RA. Systematic and integrative analysis of large gene lists using DAVID bioinformatics resources. Nat Protoc 2009;4(1):44-57.

56. da Huang W, Sherman BT, Lempicki RA. Bioinformatics enrichment tools: paths toward the comprehensive functional analysis of large gene lists. Nucleic Acids Res. 2009;37(1):1-13.

57. Ray D, Hogarth CA, Evans EB, An W, Griswold MD, Ye P. Experimental validation of Ankrd17 and Anapc10, two novel meiotic genes predicted by computational models in mice. Biol Reprod. 2012;86(4):102.

\section{Submit your next manuscript to BioMed Central and we will help you at every step:}

- We accept pre-submission inquiries

- Our selector tool helps you to find the most relevant journal

- We provide round the clock customer support

- Convenient online submission

- Thorough peer review

- Inclusion in PubMed and all major indexing services

- Maximum visibility for your research

Submit your manuscript at www.biomedcentral.com/submit
Biomed Central 